\title{
Assessment of Thyroid Dysfunction in Patients with Chronic Hepatitis C Virus Related Liver Diseases
}

\author{
Islam Mustafa Ahmed Hassan', Nader Attia Elnemr², Mohamed Ahmed \\ Ibrahim Aboelmagd ${ }^{2}$ and Fatma Rageh Moussa ${ }^{3}$ \\ ${ }^{1}$ Endemic and Infectious Diseases Specialist, Ministry of Health,Egypt. \\ ${ }^{2}$ Department of Endemic and Infectious Diseases, Faculty of Medicine, Suez Canal \\ University, Suez, Egypt. \\ ${ }^{3}$ Department of Infectious, Gastrointestinal and Hepatology Diseases, Faculty of \\ Medicine, Suez University, Suez, Egypt.
}

Corresponding Author

Fatma Rageh Moussa

Mobile:

00201126319318

E mail:

frageh2002@hotmail.c om

Key words:

Thyroid profile,

Thyroid hormones,

Hepatitis C Virus,

Liver Cirrhosis
Background and study aim: Hepatitis C virus is a hepatolymphotropic virus, which is abundant in liver and different body organs. It has a significant role in the metabolism of thyroid hormones, including peripheral conversion of $\mathrm{T} 4$ to T3.This research aimed to assess the thyroid dysfunction in patients with chronic hepatitis $\mathrm{C}$ (CHC) related liver diseases.

Methods: In this cross section study, we included 200 patients aged between 18-60 years. Patients were categorized into two groups: 50 patients with $\mathrm{CHC}$ infection without liver cirrhosis, and 150 patients had cirrhosis. The latter group were categorized based on Child-T-Pugh score into three subgroups; Child A, Child B, and Child C. Each group had 50 subjects. Patients were subjected to history taking,

\section{INTRODUCTION}

$\mathrm{HCV}$ is one of the principal etiologies of chronic hepatitis and liver cirrhosis. Over half of HCV infected patients become chronic active develop fibrosis, cirrhosis, and potentially by decompensated cirrhosis and liver cancer [1]. The prevalence of HCV is high among the Egyptian population; the majrityof them $(92.5 \%)$ are infected with genotype $4,3.6 \%$ with genotype $1,3.2 \%$ with multiple genotypes, and $<1 \%$ of patients with other genotypes [2]. In 2015, the latest Demographic Health Survey (DHS) reported a seroprevalence of $10 \%$ and viremic prevalence of $7 \%$. Between 2008 and 2015, HCV burden markedly diminished to around $30 \%$ laboratory tests to assess liver and thyroid functions, in addition to abdominal ultrasound.

Results: The mean of TSH level in noncirrhotic group was 2.57 while it was 2.81, 5.53, and 10.47 in child A, child B and $\mathrm{C}$, respectively. FT3 mean values in non-cirrhotic group were 2.88 while it was $2.23,1.42$, and 1.01 in child A, B and $\mathrm{C}$, respectively. The mean of FT4 level in non-cirrhotic group was 1.25 while it was $1.08,0.84$, and 0.77 in child A.B and C respectively.

Conclusion: Abnormalities in thyroid profile were higher among patient with cirrhosis than in those without cirrhosis. These abnormalities were strongly related to the severity of liver affection and advanced child T-Pugh scoring.

[3]. Cirrhosis is defined as a diffuse hepatic derangement that is characterized by fibrosis, and conversion of normal liver architecture into abnormal structure nodules. It represents the final histological pathway for a variety of liver diseases. The progression to cirrhosis is very variable among patients, and may occur over weeks or many years [4]. Apart from hepatic manifestations, $\mathrm{HCV}$ has extrahepatic features in multiple organ systems such as dermatologic, hematologic, renal, rheumatologic and endocrinal. Of this most important endocrinal affection is thyroid abnormalities [5]. The liver has an essential role in the metabolism of 
thyroid hormones; peripheral conversion of tetraiodothyronine (T4) to tri-iodothyronine (T3) by type one deiodinase [6]. Previous studies claimed that levels of thyroid hormones, in addition to their binding proteins are disturbed among patients with hepatic disorders, especially cirrhotic. It is reported that the reduction in whole T3 and FT3 levels is the most frequent change in plasma levels of thyroid hormones, which is linked to the impact of hepatic derangement [7]. Unfortunately, most of those patients had genotypes other than genotype 4 which is the predominant one in Egypt. The present study was conducted to assess thyroid dysfunction in patients with hepatitis $\mathrm{C}$ related liver diseases; among Egyptian patients that infected mostly genotype 4

\section{PATIENTS AND METHODS}

Two hundred patients with chronic HCV infection who attended to endemic and infectious diseases department at Suez Canal University Hospital in Ismailia city and Communicable Diseases and Research Center in Suez city. We excluded patients with evidence of autoimmune diseases, previous thyroid operations, hepatic and extra-hepatic malignancy, on corticosteroid therapy or immuno-suppressive drugs, $\mathrm{HBs} \mathrm{Ag}$ positive, on specific anti-HCV medications (DAAS) and those who refused to participate in this study.

The studied patients were divided into two main groups; Group I included 50 non cirrhotic chronic HCV patients and Group II included 150 HCV-related cirrhotic patients .The latter group was subdivided into three subgroups based on Child-T-Pugh scoring system into Child A,B and C; each group comprised 50 patients.

Child-T-Pugh scoring system is a scoring scale of five clinical features of liver disorder. These features are scored from one to three, with three denotes the highly severe derangement. The features include prothrombin time (PT), international normalized ratio (INR), serum albumin, total bilirubin, ascites, and hepatic encephalopathy.

Assessment of liver cirrhosis by abdominal ultrasound, Aspartate Aminotransferase-toPlatelet ratio index (APRI) and FIB-4). After signing the informed consent, all the studied patients were subjected to the following: Complete history taking was sought, via clinical examination confirming features of hepatic decompensation such as jaundice, encephalopathy and ascites; features of thyroid disorder or other systemic disease.

Investigations including abdominal sonography, liver function tests: aspartate transaminase (AST); alanine transaminase (ALT); prothrombin time; INR; serum bilirubin; serum albumin. In addition to complete blood count (CBC); HCV RNA PCR; serum anti-HCV antibody; Serum HBs-Ag; thyroid functions: FT3, FT4, and TSH. APRI and FIB-4 score was calculated for all patients according to the following equations APRI $=[($ AST level $/$ ULN $) /$ platelet count $\left.\left(10^{9} / \mathrm{L}\right)\right] \times 100$. For detection of cirrhosis, a cutoff score of or more than 3.5 is diagnostic [8] The FIB-4 score was determined using the following formula: FIB-4 $=$ age $\times$ AST/platelet count $\left.\left(10^{9} / \mathrm{L}\right) \times \sqrt{ } \mathrm{ALT}\right]$ a threshold value of greater than 2.5 is diagnostic [9]. IRB approval written was obtained before starting the study.

Data was statistically analyzed with SPSS version 23. Statistically significant values considered when $P$-value $<0.05$. Graphs were designed using Microsoft excel. For categorical variables, Chi-square test was used to compare two different groups. For normally distributed quantitative variables, Student t-test was used to compare two groups, while ANOVA test was used to compare between more than two groups. For abnormally distributed quantitative variables, Mann Whitney test was used to compare two groups, and.Kruskal Wallis test, to compare between more than two studied groups.

\section{RESULTS}

The study included 200 patients with a mean age of 45.96 years among patients in non-cirrhotic group, while it was 54.57 years in cirrhotic group. There was a male-gender predominance among all groups, while residence was indifferent among them. Both gender and residency were statistically insignificant between all groups (Table 1). The mean of TSH in noncirrhotic group was 2.57 while it was $2.81,5.53$ and 10.47 in child A, B and C respectively. The mean of FT3 in non-cirrhotic group was 2.88 while it was $2.23,1.42$, and 1.01 in child A, B and $\mathrm{C}$ respectively. The mean of FT4 in noncirrhotic group was 1.25 while it was $1.08,0.84$, and 0.77 in child A, B and C respectively as shown in (Table 2). 
Concerning the laboratory tests that affect TSH level, in a univariate analysis, we found that TSH is negatively and significantly correlated with CBC elements (WBCs, Hb, PLT) and serum Albumin while liver function tests (ALT, serum Bilirubin, PT), serum creatinine, presence of diabetes, duration of disease and age are dependent risk factors for it as shown in (Table 3). FT3 is negatively and significantly correlated with CBC elements (WBCs, Hb, PLT) and while liver function tests (ALT, serum Bilirubin, serum Albumin, PT), presence of diabetes, duration of disease and age are dependent risk factors for it as shown in (Table 4). FT4 correlates negatively and significantly correlated with CBC elements ( $\mathrm{Hb}, \mathrm{PLT})$ and serum Albumin while liver function tests (ALT, serum Bilirubin, PT), duration of disease and age are dependent risk factors for it as shown in (Table 5).

Table (1): Demographic data of the studied groups.

\begin{tabular}{|c|c|c|c|c|c|c|c|c|c|c|}
\hline & \multirow{2}{*}{\multicolumn{2}{|c|}{$\begin{array}{l}\text { Non cirrhotic } \\
\quad(\mathbf{n}=\mathbf{5 0})\end{array}$}} & \multicolumn{6}{|c|}{ Cirrhotic } & \multirow{3}{*}{$\begin{array}{c}\text { Test of } \\
\text { Sig. }\end{array}$} & \multirow{3}{*}{$\mathbf{p}$} \\
\hline & & & \multicolumn{2}{|c|}{$\begin{array}{c}\mathbf{A} \\
(\mathbf{n}=\mathbf{5 0})\end{array}$} & \multicolumn{2}{|c|}{$\begin{array}{c}\text { B } \\
(n=50)\end{array}$} & \multicolumn{2}{|c|}{$\begin{array}{c}\mathbf{C} \\
(\mathbf{n}=\mathbf{5 0})\end{array}$} & & \\
\hline & No. & $\%$ & No. & $\%$ & No. & $\%$ & No. & $\%$ & & \\
\hline $\begin{array}{r}\text { Gender } \\
\text { Male }\end{array}$ & 32 & 64.0 & 33 & 66.0 & 34 & 68.0 & 33 & 66.0 & \multirow{2}{*}{$\begin{array}{c}\chi^{2}= \\
0.178\end{array}$} & \multirow{2}{*}{0.981} \\
\hline Female & 18 & 36.0 & 17 & 34.0 & 16 & 32.0 & 17 & 34.0 & & \\
\hline \begin{tabular}{|l} 
Age (years) \\
Min. - Max. \\
Mean \pm SD. \\
Median \\
\end{tabular} & \multicolumn{2}{|c|}{$\begin{array}{c}27.0-61.0 \\
45.96 \pm 9.73 \\
48.0 \\
\end{array}$} & \multicolumn{2}{|c|}{$\begin{array}{c}33.0-60.0 \\
51.24 \pm 7.03 \\
52.50 \\
\end{array}$} & \multicolumn{2}{|c|}{$\begin{array}{c}38.0-64.0 \\
53.50 \pm 6.77 \\
54.50\end{array}$} & \multicolumn{2}{|c|}{$\begin{array}{c}45.0-70.0 \\
58.98 \pm 6.39 \\
59.0\end{array}$} & \multirow[t]{2}{*}{$\begin{array}{c}\mathrm{F}= \\
25.243^{*}\end{array}$} & \multirow[t]{2}{*}{$<0.001^{*}$} \\
\hline & & & \multicolumn{6}{|c|}{$\mathrm{p}_{2}=0.447, \mathrm{p}_{3}<0.001^{*}, \mathrm{p}_{4}=0.002^{*}$} & & \\
\hline $\begin{array}{c}\text { Residence } \\
\text { Urban } \\
\text { Rural }\end{array}$ & $\begin{array}{l}23 \\
27\end{array}$ & $\begin{array}{l}46.0 \\
54.0\end{array}$ & $\begin{array}{l}24 \\
26\end{array}$ & $\begin{array}{l}48.0 \\
52.0\end{array}$ & $\begin{array}{l}26 \\
24\end{array}$ & $\begin{array}{l}52.0 \\
48.0\end{array}$ & $\begin{array}{l}26 \\
24\end{array}$ & $\begin{array}{l}52.0 \\
48.0\end{array}$ & $\begin{array}{c}\chi^{2}= \\
0.540\end{array}$ & 0.910 \\
\hline
\end{tabular}

*: statistically significant $\mathrm{p}$ value, $\mathrm{p}_{2}$ : significance between group $\mathrm{A}$ and non-cirrhotic group, $\mathrm{p}_{3}$ : significance between group B and non-cirrhotic group, $\mathrm{p}_{4}$ : significance between group $\mathrm{C}$ and non-cirrhotic group, $\chi^{2}$ : chi squre test, F: ANOVA test.

Table (2): Thyroid profile of the studied groups

\begin{tabular}{|c|c|c|c|c|c|c|}
\hline Thyroid profile & $\begin{array}{c}\text { Non cirrhotic } \\
(\mathbf{n}=\mathbf{5 0})\end{array}$ & $\begin{array}{l}\text { Child A } \\
(n=50) \\
\end{array}$ & $\begin{array}{l}\text { Child B } \\
(n=50) \\
\end{array}$ & $\begin{array}{l}\text { Child C } \\
(n=50) \\
\end{array}$ & $\mathbf{H}$ & $\mathbf{P}$ \\
\hline $\begin{array}{l}\text { TSH } \\
\text { Min. - Max. } \\
\text { Mean } \pm \text { SD. } \\
\text { Median }\end{array}$ & $\begin{array}{c}0.30-4.90 \\
2.57 \pm 1.19 \\
2.45\end{array}$ & $\begin{array}{c}0.30-4.90 \\
2.81 \pm 1.34 \\
3.15\end{array}$ & $\begin{array}{c}0.30-15.70 \\
5.53 \pm 2.71 \\
5.55\end{array}$ & $\begin{array}{c}0.90-41.80 \\
10.47 \pm 7.82 \\
7.75\end{array}$ & $105.859^{*}$ & $<0.001^{*}$ \\
\hline & & \multicolumn{3}{|c|}{$\mathrm{p}_{2}<0.001^{*}, \mathrm{p}_{3}<0.001^{*}, \mathrm{p}_{4}=0.001^{*}$} & & \\
\hline \begin{tabular}{|l} 
FT3 \\
Min. - Max. \\
Mean \pm SD. \\
Median
\end{tabular} & $\begin{array}{c}1.20-4.20 \\
2.88 \pm 0.90 \\
2.85\end{array}$ & $\begin{array}{c}1.20-3.60 \\
2.23 \pm 0.71 \\
1.95\end{array}$ & $\begin{array}{c}0.20-3.30 \\
1.42 \pm 0.93 \\
1.0\end{array}$ & $\begin{array}{c}0.10-3.10 \\
1.01 \pm 0.56 \\
0.90\end{array}$ & $100.672^{*}$ & $<0.001^{*}$ \\
\hline & & \multicolumn{3}{|c|}{$\mathrm{p}_{2}<0.001^{*}, \mathrm{p}_{3}<0.001^{*}, \mathrm{p}_{4}=0.034^{*}$} & & \\
\hline $\begin{array}{l}\text { FT4 } \\
\text { Min. - Max. } \\
\text { Mean } \pm \text { SD. } \\
\text { Median }\end{array}$ & $\begin{array}{c}0.80-1.90 \\
1.25 \pm 0.26 \\
1.20\end{array}$ & $\begin{array}{c}0.60-1.80 \\
1.08 \pm 0.37 \\
1.05\end{array}$ & $\begin{array}{c}0.30-1.50 \\
0.84 \pm 0.34 \\
0.80\end{array}$ & $\begin{array}{c}0.10-1.30 \\
0.77 \pm 0.29 \\
0.75\end{array}$ & $54.851^{*}$ & $<0.001^{*}$ \\
\hline & & \multicolumn{3}{|c|}{$\mathrm{p}_{2}=0.002^{*}, \mathrm{p}_{3}<0.001^{*}, \mathrm{p}_{4}=0.448$} & & \\
\hline
\end{tabular}

*: statistically significant $\mathrm{p}$ value, $\mathrm{p}_{2}$ : significance between group $\mathrm{A}$ and non-cirrhotic group, $\mathrm{p}_{3}$ : significance between group B and non-cirrhotic group, $\mathrm{p}_{4}$ : significance between group $\mathrm{C}$ and non-cirrhotic group, H: Kruskal Wallis test. Min: minimum, Max: maximum. 
Table (3): Univariate and multivariate analysis for the parameters affecting $\operatorname{TSH}(n=150)$ for group II

\begin{tabular}{|l|c|c|c|c|}
\hline \multirow{2}{*}{ TSH } & \multicolumn{2}{|c|}{ Univariate } & \multicolumn{2}{c|}{ Multivariate } \\
\cline { 2 - 5 } & $\mathbf{B}(\mathbf{9 5 \%} \mathbf{C I})$ & $\mathbf{p}$ & $\mathbf{B}(\mathbf{9 5 \%}$ CI $)$ & P \\
\hline WBCs $\left.\mathbf{( 1 0}^{\mathbf{3}}\right)$ & $-0.791(-1.13--0.449)$ & $<0.001^{*}$ & $-0.337(-0.69-0.01)$ & 0.059 \\
\hline HB & $-1.199(-1.55--0.84)$ & $<0.001^{*}$ & $-0.129(0.64-0.38)$ & 0.621 \\
\hline PLT & $-0.088(-0.127--0.05)$ & $<0.001^{*}$ & $-0.002(-0.04-0.04)$ & 0.937 \\
\hline PT & $0.413(0.27-0.55)$ & $<0.001^{*}$ & $0.075(-0.14-0.29)$ & 0.485 \\
\hline AST & $0.056(0.03-0.08)$ & $<0.001^{*}$ & $-0.004(-0.03-0.03)$ & 0.808 \\
\hline Bilirubin & $0.025(0.0-0.05)$ & 0.054 & - & - \\
\hline Albumin & $1.871(1.38-2.36)$ & $<0.001^{*}$ & $0.465(-0.37-1.30)$ & 0.274 \\
\hline S.cr & $-3.830(-4.98--2.68)$ & $<0.001^{*}$ & $-0.828(-0.244-0.79)$ & 0.313 \\
\hline AFP & $2.052(0.91-3.20)$ & $0.001^{*}$ & $-0.157(-1.29-0.97)$ & 0.783 \\
\hline RBS & $0.042(-0.03-0.114)$ & 0.242 & - & - \\
\hline Gender (Female) & $-0.007(-0.02-0.004)$ & 0.210 & - & - \\
\hline Age (years) & $-0.093(-2.07-1.89)$ & 0.926 & - & 0.118 \\
\hline Diabetic & $0.351(0.239-0.463)$ & $<0.001^{*}$ & $0.119(-0.03-0.27)$ & 0.101 \\
\hline Duration of disease & $2.500(0.551-4.448)$ & $0.012^{*}$ & $1.389(-0.27-3.05)$ & 0.150 \\
\hline
\end{tabular}

*Statistically significant $\mathrm{p}$ value. B: beta coefficient, CI: confidence interval, WBCs: white blood cells, HB: hemoglobin, PLT, platelets, ALT: alanine transaminase, AST: aspartate transaminase, S.cr: serum creatinine, AFP: alpha feto-protein, RBS, random blood sugar.

Table (4): Univariate and multivariate analysis for the parameters affecting FT3 $(n=150)$ for group II

\begin{tabular}{|l|c|c|c|c|}
\hline \multirow{2}{*}{ FT3 } & \multicolumn{2}{|c|}{ Univariate } & \multicolumn{2}{c|}{${ }^{\text {\#Multivariate }}$} \\
\cline { 2 - 5 } & $\mathbf{B}(\mathbf{9 5 \%} \mathbf{C I})$ & $\mathbf{p}$ & $\mathbf{B}(\mathbf{9 5 \%} \mathbf{C I})$ & P \\
\hline WBCs $\left(\mathbf{1 0}^{\mathbf{3}}\right)$ & $0.098(0.043-0.152)$ & $0.001^{*}$ & $0.018(-0.040-0.075)$ & 0.546 \\
\hline HB & $0.180(0.123-0.237)$ & $<0.001^{*}$ & $0.070(-0.015-0.154)$ & 0.106 \\
\hline PLT & $0.013(0.007-0.019)$ & $<0.001^{*}$ & $0.002(-0.005-0.009)$ & 0.569 \\
\hline ALT & $-0.053(-0.075--0.030)$ & $<0.001^{*}$ & $0.012(-0.022-0.046)$ & 0.478 \\
\hline AST & $-0.007(-0.12--0.003)$ & $0.002^{*}$ & $0.0(-0.005-0.005)$ & 0.890 \\
\hline Bilirubin & $0.0(-0.004-0.004)$ & 0.953 & - & - \\
\hline Albumin & $-0.268(-0.347--0.188)$ & $<0.001^{*}$ & $-0.106(-0.244-0.032)$ & 0.132 \\
\hline S.cr & $0.544(0.360-0.728)$ & $<0.001^{*}$ & $0.111(-0.155-0.378)$ & 0.409 \\
\hline AFP & $-0.167(-0.352-0.017)$ & 0.075 & - & - \\
\hline RBS & $-0.011(-0.022-0.001)$ & 0.061 & - & - \\
\hline Gender (Female) & $0.0(-0.002-0.002)$ & 0.849 & - & - \\
\hline Age (years) & $-0.249(-0.556-0.058)$ & 0.111 & - & - \\
\hline Diabetic & $-0.040(-0.059--0.022)$ & $<0.001^{*}$ & $0.009(-0.016-0.033)$ & 0.474 \\
\hline Duration of disease & $-0.244(-0.552-0.065)$ & 0.120 & - & - \\
\hline
\end{tabular}

*Statistically significant $\mathrm{p}$ value. B: beta coefficient, CI: confidence interval, WBCs: white blood cells, HB: hemoglobin, PLT, platelets, ALT: alanine transaminase, AST: aspartate transaminase, S.cr: serum creatinine, AFP: alpha feto-protein, RBS, random blood sugar. 
Table (5): Univariate and multivariate analysis for the parameters affecting FT4 $(n=150)$ for group II

\begin{tabular}{|l|c|c|c|c|}
\hline \multirow{2}{*}{ FT4 } & \multicolumn{2}{|c|}{ Univariate } & \multicolumn{2}{c|}{ "Multivariate } \\
\cline { 2 - 5 } & \multicolumn{1}{|c|}{ B (95\% CI) } & P & B (95\% CI) & P \\
\hline WBCs $\left(\mathbf{( 1 0}^{\mathbf{3}}\right)$ & $0.020(-0.003-0.042)$ & 0.084 & - & - \\
\hline HB & $0.049(0.025-0.073)$ & $<0.001^{*}$ & $0.031(-0.006-0.068)$ & 0.101 \\
\hline PLT & $0.003(0.0-0.005)$ & $0.031^{*}$ & $0.0(-0.003-0.003)$ & 0.937 \\
\hline PT & $-0.011(-0.020--0.001)$ & $0.024^{*}$ & $0.009(-0.005-0.024)$ & 0.211 \\
\hline ALT & $-0.002(-0.004-0.0)$ & $0.048^{*}$ & $0.0(-0.002-0.002)$ & 0.890 \\
\hline AST & $0.0(-0.002-0.001)$ & 0.619 & - & - \\
\hline Bilirubin & $-0.067(-0.101--0.032)$ & $<0.001^{*}$ & $-0.025(-0.085-0.034)$ & 0.402 \\
\hline Albumin & $-0.153(0.076-0.230)$ & $<0.001^{*}$ & $0.054(-0.062-0.170)$ & 0.360 \\
\hline S.cr & $-0.064(-0.137-0.010)$ & 0.089 & - & - \\
\hline AFP & $-0.001(-0.006-0.003)$ & 0.556 & - & - \\
\hline RBS & $-005(-0.001-0.001)$ & 0.826 & - & - \\
\hline Gender (Female) & $0.027(-0.096-0.150)$ & 0.434 & - & - \\
\hline Age (years) & $-0.010(-0.017--0.002)$ & $0.015^{*}$ & $0.007(-0.004-0.017)$ & 0.196 \\
\hline Diabetic & $-0.091(-0.214-0.032)$ & 0.145 & - & - \\
\hline Duration of disease & $-0.022(-0.031--0.012)$ & $<0.001^{*}$ & $-0.017(-0.032--0.001)$ & $0.037^{*}$ \\
\hline
\end{tabular}

*Statistically significant $\mathrm{p}$ value. B: beta coefficient, CI: confidence interval, WBCs: white blood cells, HB: hemoglobin, PLT, platelets, ALT: alanine transaminase, AST: aspartate transaminase, S.cr: serum creatinine, AFP: alpha feto-protein, RBS, random blood sugar.

\section{DISCUSSION}

Since there is an alteration in thyroid profile was noticed among patients with $\mathrm{CHC}$, we aimed to assess the thyroid profile among them. In this cross section study, we included 200 patients with CHC. We classified patients into two groups: cirrhotic and non-cirrhotic. The former group was subdivided into three more groups based on Child-T-Pugh scoring system among those patients we evaluated the thyroid profile, liver and kidney function tests, and CBC.

The result of this research revealed a decrease in the level of FT3 in cirrhotic patients (Group II ) and it was statistically significant. When the serum levels of FT3 in different subgroups were compared, Child A group was within the normal range meanwhile child $\mathrm{C}$ patients had the lowest levels. This result is in agreement with Kharb [6], Mansour [9], El-Kabbany [11], Eshraghian [12] who documented that dysregulation and dysfunction of thyroid hormones were in cirrhotic patients. Furthermore, our results are also in agreement with Malik [13] who reported that the level of FT3 was significantly low in patients with chronic hepatitis $\mathrm{C}$ in comparison to control.

Our results also revealed that the level of FT4 was statistically significant lower in cirrhotic patients (Group II). When comparing the mean serum level of FT4 among different subgroups;
$\mathrm{A}, \mathrm{B}$, and $\mathrm{C}$ we found that the lowest levels were in Child $\mathrm{C}$ group, followed by the Child $\mathrm{B}$ group, meanwhile Child A group was within the normal range. These results are in agreement with Kabadi [14] who reported that there was low levels of T3 and T4 in patients with advanced liver cirrhosis. In addition, our study was in line with Kayacetin [15] and Antonelli et al [10] who reported that FT4 level was significantly lower in cirrhotic patients. They proposed that the previous findings might be reliant on the severity of hepatocellular damage and might be reversed on improvement of liver functions, so that we can consider T4 and T3 levels as useful prognostic indices.

Conversely, our previous outcomes were in disagreement with Malik [13] who recorded that most of chronic hepatitis $\mathrm{C}$ had normal thyroid function; normal TSH and FT4 levels. Moreover, they were in disagreement with Huang [16] who reported that levels of FT4 and TSH were within normal range in chronic liver disease patients. They also were in disagreement with Antonelli et al [10] who recorded a marked reduction in FT3 and increase in the level of FT4 in both cirrhotic and non-cirrhotic chronic hepatitis $\mathrm{C}$ patients. These controversial results might be due to the difference in genetic background of patients, geographic distribution, and different environmental factors; like iodine intake and presence of other infectious agents. 
Our study revealed a highly significant level of TSH in cirrhotic patients (Group II) when compared to non-cirrhotic (Group I). When comparing the mean TSH serum level in different subgroups; $\mathrm{A}, \mathrm{B}$, and $\mathrm{C}$ we found that Child $\mathrm{C}$ group had the highest level followed by the Child $\mathrm{B}$ group, meanwhile normal range was found in Child A group.

This result was in agreement with Antonelli et al. [10], Moustafa [17] and Mansour [9], who found that serum TSH level was higher in decompensated cirrhotic hepatitis $\mathrm{C}$ patients than both chronic hepatitis and compensated cirrhotic patients. However, that result were in disagreement with Kharb [6] who found that TSH level was lower in patients with chronic liver disease than control; they proposed an explanation for that finding that the increased level of inflammatory cytokines in chronic liver disease patients might negatively affect the hypothalamic-thyroid axis. These results also were in disagreement with Kayacetin [15] who reported that the level of TSH had no significant difference between cirrhotic and noncirrhotic chronic hepatitis C patients. These different results as mentioned before might be due to differences in HCV genotyping, environmental factors, geographic distribution, and genetic background.

The present study showed that serum albumin level, serum bilirubin, prothrombin time and Child -T-Pugh score are dependent risk factor for FT3 and FT4 abnormalities. These results are similar to those of Borzio [18] who observed that serum FT3 was significantly correlated with serum bilirubin, serum albumin, and Prothrombin time.

\section{CONCLUSION}

Cirrhotic hepatitis $\mathrm{C}$ patients have thyroid abnormalities higher than non-cirrhotic patients do. It is intensely related to the severity of liver affection and the advancing of child score. S.Bilirubin, Prothrombin time, duration of disease and degree of liver cirrhosis are dependent risk factor for TSH abnormalities. We can consider TSH, FreeT4 and Free T3 to be useful prognostic indices.

Ethical approval: Consent was taken from each participant, who was assured about the confidentiality of his information. The Faculty of
Medicine, Suez Canal University Research Ethics Committee approved the study.

Funding: None

Conflicts of interest: There are no conflicts of interest.

\section{REFERENCES}

1. World Health Organization. Hepatitis C, 2016; (fact sheet no. 164, updated July 2013).

2. Kouyoumjian SP, Chemaitelly H, Abu-Raddad LJ. Characterizing hepatitis $\mathrm{C}$ virus epidemiology in Egypt: systematic reviews, meta-analyses, and meta-regressions. Scientific Reports 2018; 8(1): 1-17.

3. Kandeel A, Genedy M, El-Refai S, Maha T. The prevalence of hepatitis $C$ virus infection in Egypt 2015: implications for future policy on prevention and treatment. Liver International 2017; 37(1): 45-53.

4. Tsochatzis E, Bosch J, Burroughs AK. Liver cirrhosis. The Lancet 2014; 383 (9930): 17491761.

5. Jadali Z. Autoimmune thyroid disorders in hepatitis $\mathrm{C}$ virus infection: Effect of interferon therapy. Indian Journal of Endocrinology and Metabolism 2013; 17(1): 69.

6. Kharb S, Garg MK, Puri P, Sharad S. Assessment of Thyroid and Gonadal Function in Liver Diseases. Indian Journal of Endocrinology and Metabolism 2015; 19: 89-94.

7. Lin ZH, Xin YN, Dong QJ, Wang Q, Jiang XJ, Zhan SH, et al. Performance of the aspartate aminotransferase-to-platelet ratio index for the staging of hepatitis C-related fibrosis: an updated meta-analysis. Hepatology 2011; 53: 726-36.

8. Martínez SM, Crespo G, Navasa M, Forns X. Noninvasive assessment of liver fibrosis. Hepatology 2011; 53(1):325-35. PMID: 21254180.

9. Mansour-Ghanaei F. Decreased Serum Total T3 Level in Hepatitis B and C Related Cirrhosis by Severity of Liver Damage. Annals of Hepatology 2012; 11: 667-671.

10. Antonelli A, Ferri C, Galeazzi M, Giannitti C, Manno D, Mieli-Vergani G, et al. Thyroid disorders in chronic hepatitis C. Am J Med 2004; 117: 10-3.

11. El-Kabbany ZA. Thyroid and Hepatic Haemodynamic Alterations among Egyptian Children with Liver Cirrhosis. ISRN Gastroenterology 2012; 595-734. 
12. Eshraghian A, Taghavi SA. Systematic Review: Endocrine Abnormalities in Patients with Liver Cirrhosis. Archives of Iranian Medicine 2014; 17: 713-721.

13. Malik R, Hodgson $\mathrm{H}$. The relationship between the thyroid gland and the liver. QJM: $A n$ International Journal of Medicine 2002; 95(9): pp.559-569.

14. Kabadi UM, Premachandra BN. Serum T3 and Reverse T3 Levels in Hepatic Cirrhosis: Relation to Hepatocellular Damage and Normalization on Improvement in Liver Dysfunction. The American Journal of Gastroenterology 1983; 78: 750-755.

15. Kayacetin E, Kisakol G, Kaya A. Low Serum Total Thyroxine and Free Triiodothyronine in Patients with Hepatic Encephalopathy due to Non-Alcoholic Cirrhosis. Swiss Medical Weekly 2003; 133: 210-213.
16. Huang MJ, Liaw YF. Clinical Associations between Thyroid and Liver Diseases. Journal of Gastroenterology and Hepatology 1995; 10: 344-350.

17. Moustafa AH, Ali EM, Mohamed TM and Abdou HI: Oxidative Stress and Thyroid Hormones in Patients with Liver Diseases. European Journal of Internal Medicine 2009; 20: 703-708.

18. Borzio M, Caldara R, Borzio F, Piepoli V, Rampini $\mathrm{P}$, and Ferrari $\mathrm{C}$. Thyroid function tests in chronic liver disease: evidence for multiple abnormalities despite clinical euthyroidism. Gut 1983; 24(7): 631-636. 